\title{
Analysis of Genotype-Environment Interaction and Yield Stability of Introduced Upland Rice in the Groundnut Basin Agroclimatic Zone of Senegal
}

\author{
Ghislain Kanfany ${ }^{(D},{ }^{1}$ Mathieu Anatole Tele Ayenan $\left(\mathbb{D},{ }^{2}\right.$ \\ Yedomon Ange Bovys Zoclanclounon $\mathbb{D}^{3},{ }^{3}$ Talla Kane, ${ }^{4}$ Malick Ndiaye, ${ }^{1}$ Cyril Diatta $\mathbb{D}^{1}$ \\ Jeannot Diatta, ${ }^{1}$ Tala Gueye, ${ }^{4}$ and Amadou Fofana ${ }^{1}$ \\ ${ }^{1}$ Centre National de Recherches Agronomiques de Bambey, Institut Sénégalais de Recherches Agricoles, B.P.53 Bambey, \\ Diourbel, Senegal \\ ${ }^{2}$ West Africa Centre for Crop Improvement (WACCI), College of Basic and Applied Sciences, University of Ghana, Legon, Ghana \\ ${ }^{3}$ Centre D'Etudes Régional pour L'Amélioration de L'Adaptation à La Sécheresse, BP 3320, Route de Khombole, Thies, Senegal \\ ${ }^{4}$ Ecole Nationale Supérieure D'Agriculture (ENSA), Route de Khombole, Thies, Senegal
}

Correspondence should be addressed to Yedomon Ange Bovys Zoclanclounon; angez9914@gmail.com

Received 14 June 2021; Accepted 28 September 2021; Published 28 October 2021

Academic Editor: Innocenzo Muzzalupo

Copyright (c) 2021 Ghislain Kanfany et al. This is an open access article distributed under the Creative Commons Attribution License, which permits unrestricted use, distribution, and reproduction in any medium, provided the original work is properly cited.

\begin{abstract}
Identification of highly performing varieties under Senegalese environment is crucial to sustain rice production. Genotypeenvironment interaction and stability performance on the grain yield of ten upland rice genotypes were investigated across 11 environments in Senegal during the rainy seasons of 2016 and 2017 to identify adapted varieties. The experiment was conducted using a randomized complete block design with three replications at each environment. Data on grain yield were recorded and analyzed using the additive main effects and multiplicative interaction (AMMI) model. The combined analysis of variance revealed that the grain yield was significantly affected by environment $(67.9 \%)$, followed by genotype $\times$ environment $(\mathrm{G} \times \mathrm{E})$ interaction (23.6\%) and genotype (8.5\%). The first two principal component axes were highly significant with 37.5 and $26 \%$ of the total observed $\mathrm{G} \times \mathrm{E}$ interaction variation, respectively. GGE biplot grouped the environments into four potential megaenvironments. Based on the yield stability index parameter and ranking GGE biplot, NERICA 8 and ART3-7-L9P8-1-B-B-1 were stable and high-yielding varieties compared to the local check NERICA 6 . These varieties should be proposed for cultivation in order to sustain the rice production in the southern part of the groundnut basin of Senegal and used as parental lines in rice breeding program for grain yield improvement.
\end{abstract}

\section{Introduction}

Globally, rice is one of the most important cereals grown as staple food crop [1]. By 2035, it is estimated that supplementary 112 million metric tons of rice will be needed to fulfill human consumption [2]. In the Sahelian countries including Senegal, rice is the second most cultivated cereal after pearl millet. Despite the effort of Senegalese government for boosting local rice production, more than 1000 metric tons of rice were imported in 2018-
2019, which was worth about $\$ 339$ millions [3]. To meet the increasing rice demand, available agricultural practices, water management, and varietal opportunities should be exploited.

Rice is produced in various agroecologies and cropping systems including rain fed upland and lowland, irrigated, and mangrove [4]. Although upland rice represents a small amount (around 11\%) of global rice production in the world, it plays a crucial role in local rice production in arid and semiarid countries [5]. Due to climate change effects, a 
limitation of water resource for lowland rice cultivation has become a challenge. The upland rice appears as a promising sustainable crop that can contribute to cope with food security issue [6]. Development of new upland rice varieties has become a serious research interest for some Asian countries such as Vietnam [7], India [8], and China [9]. With regard to Africa, recent efforts were done by Africa Rice and their collaborators in order to develop upland rice varieties adapted to growing conditions in tropical regions. The successful exploitation of the varieties developed by Africa Rice required adaptability trials under local growing conditions. For this purpose, multienvironment trials are conducted.

Many plant breeding programs performed multienvironment trials in order to assess the response of plant material in several locations [10]. The key objective of plant breeders is to develop varieties with a wide adaptation to various environments. Multienvironment trial data have been revealed useful in identifying varieties with a high grain yield for diverse cereals such as maize $[11,12]$, sorghum [13], and irrigated [14] and upland rice [15]. Classical statistical models were developed to assess and provide useful information to exploit genotype by environment interactions. These models include analysis of variance, additive main effects and multiplicative interaction (AMMI), site regression (SREG), genotype regression (GREG), shifted multiplicative, completely multiplicative, and genotype by environment biplot (GGE). Among these models, AMMI and GGE have been widely adopted by plant breeders. The AMMI model combined analysis of variance and principal component analysis [16], while GGE biplot is based on genotype and environment scores. For the AMMI model, singular value decomposition is applied to the twice-centered two-way data, capturing genotype by environment only. In contrast, GGE captures Genotype and Genotype by Environment by applying singular value decomposition to environment-centered two-way data [17].

Previous studies highlighted the use of genotype by environment model in upland rice breeding for drought stress tolerance $[18,19]$, adaptability and yield stability assessment [20], optimum sowing date identification [21], and root morphology [22]. The aim of the present study was to identify high yielding and stable upland rice genotypes for cultivation in the groundnut basin agroecological zone of Senegal.

\section{Materials and Methods}

The experiments were carried out during the rainy seasons of 2016 and 2017 in 11 environments located in the groundnut basin agroecological zone (Table 1).

This agroecological zone, which covers over $30 \%$ of the land area of Senegal and $65 \%$ of the cultivated area, is characterized by a highly variable rainfall pattern which is monomodal with an annual mean of $600 \mathrm{~mm}$. The rainy season usually begins in June-July, ends in October, and is followed by a long dry season, which begins in November and lasts till June. The soil texture in the 11 environments is clay or sandy loam.
Ten genotypes were used for the experiment (Table 2).

These included nine genotypes selected based on farmers' preferences and agromorphologic performance and NERICA 6, the most popular variety cultivated in this region as a check. The experiments were laid out in a randomized complete block design with three replications. A plot consisted of 12 rows of five meters per plot. The spacing was $25 \mathrm{~cm}$ between rows and $20 \mathrm{~cm}$ between hills. All the recommended cultivation practices for upland rice cultivation were applied. The grain yield data per plot was recorded over the different environments.

An initial analysis of variance was performed for each of the 11 environments using Genstat software version 12.1 to determine the genotype effect. After this individual environment analysis of variance, the homogeneity between residual variances was determined, and a joint analysis of variance using Genstat software was performed to assess the genotype and environment effect and the magnitude of the $\mathrm{G} \times \mathrm{E}$ interaction. Additive main effect and multiplicative interaction (AMMI) model implemented in statistical software Genstat was used to adjust the main or additive genotype-environmental effects by analysis of variance, in addition to the adjustment of the multiplicative effects for the $\mathrm{G} \times \mathrm{E}$ interaction by principal component analysis. Assuming $\mu$ is the grand mean of upland rice genotypes yield, $\alpha_{g}$ is the genotype deviation of the grand mean, $\beta_{e}$ is the environment deviation, $\lambda_{n}$ is singular value for interaction principal component (IPC) $n$ and $\lambda_{n}^{2}$ is the corresponding eigenvalue, $\gamma_{\mathrm{gn}}$ is the eigenvector for genotype $g$ and component $n, \delta_{\text {en }}$ is the eigenvector for environment $e, \rho_{e}$ is the residual, $\kappa_{r(e)}$ is the block effect for replication $r$ within environment $e$ and $\varepsilon_{\text {ger }}$ is the error, the yield of genotype $g$ in environment $e$ for replication $r\left(Y_{\mathrm{ger}}\right)$ is expressed by Gauch's model [23]:

$$
Y_{\mathrm{ger}}=\mu+\alpha_{g}+\beta_{e}+\sum_{n} \lambda_{n} \gamma_{\mathrm{gn}} \delta_{\mathrm{en}}+\rho_{e}+\kappa_{r(e)}+\varepsilon_{\mathrm{ger}},
$$

Based on relative contributions of the IPC 1 and 2 axis scores to genotype by environment interaction effect, the AMMI stability value (ASV) was computed using the following formula described by Danquah et al. [24]:

$$
\mathrm{ASV}=\sqrt{\left[\frac{\mathrm{IPC} 1_{\text {Sum of squares }}}{\mathrm{IPC} 2_{\text {Sum of squares }}}\left(\mathrm{IPC} 1_{\text {score }}\right)\right]^{2}+\left(\mathrm{IPC} 2_{\text {score }}\right)^{2}}
$$

Using yield-based genotype ranking and ranking based on the AMMI stability value, the yield stability index was calculated as follows:

$$
\begin{aligned}
\text { yield stability index }= & \text { ranking based on the AMMI stability value } \\
& + \text { ranking based on yield. }
\end{aligned}
$$

Lower are AMMI stability value and yield-based ranking values, more stable and high yielding is the genotype [25]. 
TABLE 1: Environment, rainfall ( $\mathrm{mm})$, soil texture, longitude, and latitude at each experiment environment.

\begin{tabular}{|c|c|c|c|c|c|}
\hline Environment & Code & Rainfall (mm) & Soil texture & Latitude & Longitude \\
\hline Diama fara (2017) & DF17_.E1 & 723 & Sandy loam & $13^{\circ} 55^{\prime} 56.32^{\prime \prime} \mathrm{N}$ & $15^{\circ} 42^{\prime} 0.14^{\prime \prime} \mathrm{O}$ \\
\hline Medinatou salam (2016) & MeS16_E2 & 668 & Clay & $13^{\circ} 49^{\prime} 16.35^{\prime \prime} \mathrm{N}$ & $15^{\circ} 28^{\prime} 0.43^{\prime \prime} \mathrm{O}$ \\
\hline Medinatou salam (2017) & MeS17_.E3 & 615 & Clay & $13^{\circ} 49^{\prime} 16.35^{\prime \prime} \mathrm{N}$ & $15^{\circ} 28^{\prime} 0.43^{\prime \prime} \mathrm{O}$ \\
\hline Maka sacoumba (2017) & MaS17_.E4 & 301 & Clay & $13^{\circ} 49^{\prime} 49.14^{\prime \prime} \mathrm{N}$ & $15^{\circ} 39^{\prime} 39.58^{\prime \prime} \mathrm{O}$ \\
\hline Nioro (2016) & N16_.E5 & 909 & Sandy loam & $13^{\circ} 45^{\prime} 30.64^{\prime \prime} \mathrm{N}$ & $15^{\circ} 47^{\prime} 17.50^{\prime \prime} \mathrm{O}$ \\
\hline Nioro (2017) & N17_.E6 & 702 & Sandy loam & $13^{\circ} 45^{\prime} 30.64^{\prime \prime} \mathrm{N}$ & $15^{\circ} 47^{\prime} 17.50^{\prime \prime} \mathrm{O}$ \\
\hline Ndama (2016) & Nd16_.E7 & 555 & Clay & $13^{\circ} 49^{\prime} 49.19^{\prime \prime} \mathrm{N}$ & $15^{\circ} 39^{\prime} 39.72^{\prime \prime} \mathrm{O}$ \\
\hline Bowou (2016) & B16_.E8 & 591 & Sandy loam & $13^{\circ} 40^{\prime} 57.96^{\prime \prime} \mathrm{N}$ & $15^{\circ} 41^{\prime} 35.19^{\prime \prime}$ \\
\hline Medina ngueyene (2016) & MN_.E9 & 588 & Clay & $13^{\circ} 39^{\prime} 44.19^{\prime \prime} \mathrm{N}$ & $15^{\circ} 42^{\prime} 0.14^{\prime \prime} \mathrm{O}$ \\
\hline Medina ngueyene (2017) & MN_.E10 & 591 & Clay & $13^{\circ} 39^{\prime} 44.19^{\prime \prime} \mathrm{N}$ & $15^{\circ} 42^{\prime} 0.14^{\prime \prime} \mathrm{O}$ \\
\hline Keur babou penda (2017) & KBP17__E11 & 492 & Clay & $13^{\circ} 45^{\prime} 23.12^{\prime \prime} \mathrm{N}$ & $16^{\circ} 19^{\prime} 35.69^{\prime \prime} \mathrm{O}$ \\
\hline
\end{tabular}

TABLE 2: List of upland rice genotypes used in this study.

\begin{tabular}{lcc}
\hline Genotype & Name & Origin \\
\hline G1 & ART16-13-13-2-2-B-1-B-1-B & Africa rice \\
G2 & ART3-9-L6P2-B-B & Africa rice \\
G3 & ART16-12-22-1-3-1-1-B-1-B & Africa rice \\
G4 & CNAX 3031-78-2-1-7 & Brazil \\
G5 & ART16-17-7-18-1-B-1-B-1-B & Africa rice \\
G6 & BRS CONAI & Brazil \\
G7 & NERICA 8 & Africa rice \\
G8 & NERICA 14 & Africa rice \\
G9 & ART3-7-L9P8-1-B-B-1 & Africa rice \\
G10 & NERICA 6 (check) & Africa rice \\
\hline
\end{tabular}

Biplot graphs with the grain yield data were plotted using the package GGEBiplots following the GGE biplot model defined by Yan [17] in $R$ 3.6.0 as follows:

$$
y_{i j}=\sum_{n=1}^{r} \lambda_{n} \xi_{i n} \eta_{j n}
$$

where $r$ is the number of principal components required to approximate the original data, $\lambda_{n}$ is the singular value of principal components, $\xi_{\text {in }}$ and $\xi_{j n}$ are the $i^{\text {th }}$ genotype score and the $j^{\text {th }}$ environment score for principal components, respectively, and $y_{i j}$ is the response yield according the $i^{\text {th }}$ genotype in the $j^{\text {th }}$ environment.

\section{Results}

3.1. Significant Genotype by Environment Interaction. Results of analysis of variance for yield data of upland rice genotypes using AMMI model are reported in Table 3.

All the sources of variation effects were significant $(P<0.01)$. The highest part of the total variation was attributable to environmental effects (68\%), followed by genotype by environment interaction (24\%) and genotype $(8 \%)$. The initial first two IPCA were highly significant and contributed to $63.5 \%$ of the total genotype by environment variation.

The mean performance of all the ten upland rice genotypes across the 11 environments showed significant genetic variability for grain yield (Table 3 ). NERICA 14 had the highest grain yield (4764 $\mathrm{kg} \mathrm{ha}^{-1}$ ), while CNAX 3031-782-1-7 had the lowest grain yield $\left(2751 \mathrm{~kg} \mathrm{ha}^{-1}\right)$, followed by the standard check NERICA $6\left(3028 \mathrm{~kg} \mathrm{ha}^{-1}\right)$ across all environments (Table 4).

3.2. Potential Mega-Environments. We assessed the "whichwon-where" pattern to identify the variety with the best performance in each megaenvironment. The biplot captured $68.96 \%$ of the variation in the data (Figure 1).

This suggests that the biplot provides a reliable visualization of the actual data. The 11 environments fell into four sectors with different wining varieties, suggesting that there was a crossover, and target environment could be divided into four different megaenvironments. G5 (ART16-17-7-181-B-1-B-1-B) and G9 (ART3-7-L9P8-1-B-B-1) were the highest yielding in the megaenvironment made up of E1, E6, E11, and E8. In the megaenvironment composed of E7, E4, E5, and E2, G8 (NERICA 14) was the winning variety in terms of grain yield. G3 (ART16-12-22-1-3-1-1-B-1-B) was the winning variety in the megaenvironment $\mathrm{E} 3$, while G4 (CNAX 3031-78-2-1-7) and G10 (NERICA 6) were the winning varieties in E9.

\subsection{Stability and Mean Performance across Environments.} Additive main effect and multiplicative interaction stability value (ASV) and yield stability index (YSI) ranked the genotypes based on the least score (Table 4).

Low scores of ASV represent the most stable genotypes, while low score of YSI represent the most stable and high yielding genotypes. Based on the ASV, the most stable genotype for grain yield was BRS CONAI since it had the lower ASV value, followed by ART3-9-L6P2-B-B and NERICA 8. NERICA 14 had the highest yield across environments, but it was the least stable genotype because it had the highest ASV value. In terms of YSI, ART3-9-L6P2-B-B, followed by BRS CONAI, NERICA 8, and ART3-7-L9P8-1-B-B-1 were the best genotypes that combined high yield with stability. CNAX 3031-78-2-1-7, followed by ART16-12-22-1-3-1-1-B1 -B and NERICA 6 , had the highest YSI and was considered as low yielding and unstable genotypes. Meanwhile, NERICA 14 and ART3-7-L9P8-1-B-B-1 exhibited earlier flowering status among the tested genotypes.

The patterns of mean performance and stability of the varieties across environments patterns were also graphically presented (Figure 2) using the GGE biplot model. 
TABLE 3: Additive main effects and multiplicative interaction analysis of variance for grain yield $\left(\mathrm{t} \mathrm{ha}^{-1}\right)$ of the genotypes across environments.

\begin{tabular}{lcccc}
\hline Source & df & SS & MS & Contribution to the SS (\%) \\
\hline Treatment & 109 & 1332169710 & 12221740 & $12541758^{* * *}$ \\
Genotypes (G) & 9 & 112875818 & $90442749^{* * *}$ & 6.5 \\
Environment (E) & 10 & 904427485 & $3498516^{* * *}$ & 23.6 \\
G $\times$ E & 90 & 314866407 & $6554514^{* * *}$ & 37.5 \\
IPCA1 & 18 & 117981244 & $5118672^{* * *}$ & 26.0 \\
IPCA2 & 16 & 81898746 & $2889182^{\text {ns }}$ & 12.1 \\
IPCA3 & 14 & 40448548 & $1320957^{\text {ns }}$ & $1807983^{\text {ns }}$ \\
Residuals & 30 & 39628719 & & \\
Error & 198 & 357980618 & & \\
\hline
\end{tabular}

df: degree of freedom, SS: sum of squares, MS: mean square.

TABLE 4: Flowering and grain yield performance and stability parameters of the tested genotypes.

\begin{tabular}{|c|c|c|c|c|c|c|}
\hline Genotypes & Flowering (DAS) & Grain yield $\left(\mathrm{kg} \mathrm{ha}^{-1}\right)$ & IPCAg1 & IPCAg2 & ASV & YSI \\
\hline ART16-13-13-2-2-B-1-B-1-B & 65 & 3889 & 3.75206 & 21.18663 & 21.9 & 9 \\
\hline ART3-9-L6P2-B-B & 71 & 4102 & -0.62371 & 16.49345 & 16.5 & 5 \\
\hline ART16-12-22-1-3-1-1-B-1-B & 69 & 3341 & 38.53965 & -22.01051 & 59.7 & 17 \\
\hline CNAX $3031-78-2-1-7$ & 73 & 2751 & 36.89505 & 2.46959 & 53.2 & 18 \\
\hline ART16-17-7-18-1-B-1-B-1-B & 68 & 3581 & -34.81286 & 6.68594 & 50.6 & 13 \\
\hline BRS CONAI & 65 & 3601 & -6.87921 & 3.32973 & 10.5 & 7 \\
\hline NERICA 8 & 67 & 4038 & -13.17107 & -8.63944 & 20.8 & 7 \\
\hline NERICA 14 & 64 & 4764 & -14.17198 & -56.38124 & 60.0 & 11 \\
\hline ART3-7-L9P8-1-B-b-1 & 64 & 4404 & -34.18457 & 14.92481 & 51.5 & 9 \\
\hline NERICA 6 & 71 & 3028 & 24.65662 & 21.94104 & 41.7 & 14 \\
\hline
\end{tabular}

DAS: days after sowing, IPCAg1: component 1, IPCAg2: component 2, ASV: AMMI stability value, YSI: yield stability index.

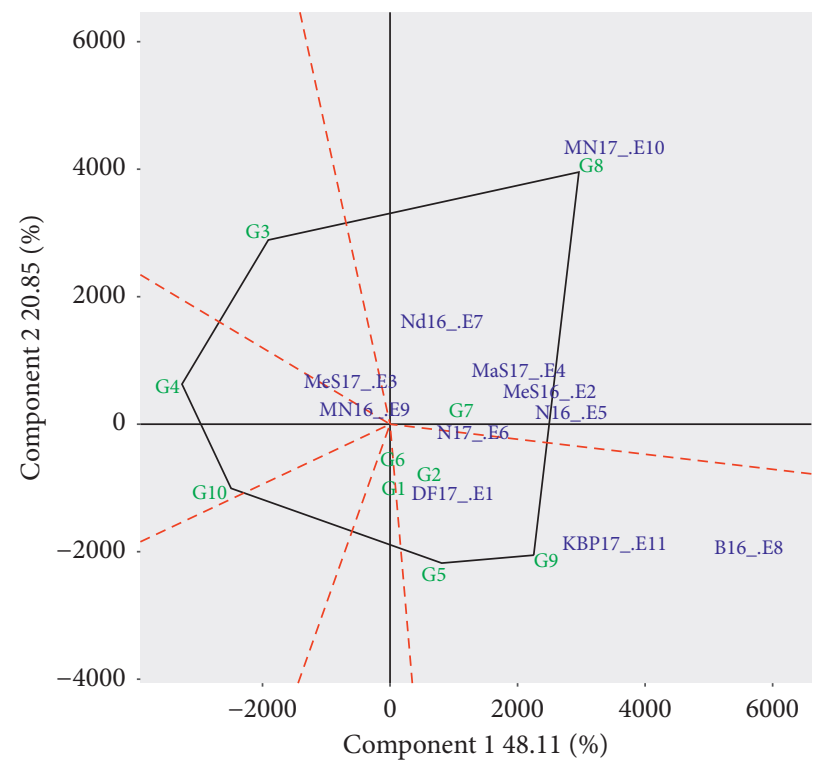

FIgURE 1: The which-won-where GGE biplot view depicting the performance of varieties in relation to potential megaenvironments (delineated in red dash lines) based on the genotype focused singular-value partitioning and environment-centered model. See Tables 1 and 2 for genotypes and environments code names, respectively.

The biplot explained $68.96 \%$ of the variation for grain yield. The principal components 1 and 2 accounted for 48.11 and $20.85 \%$ of the total variation, respectively. Based on the average-environment coordination (AEC), the genotypes NERICA 14 (8), ART3-7-L9P8-1-B-B-1 (9), and NERICA 8
(7) appeared as the highest yielding genotypes among which NERICA 8 and ART3-7-L9P8-1-B-B-1 were the most stable across environment. CNAX 3031-78-2-1-7, NERICA 6, and ART16-12-22-1-3-1-1-B-1-B were the lowest yielding genotypes. 


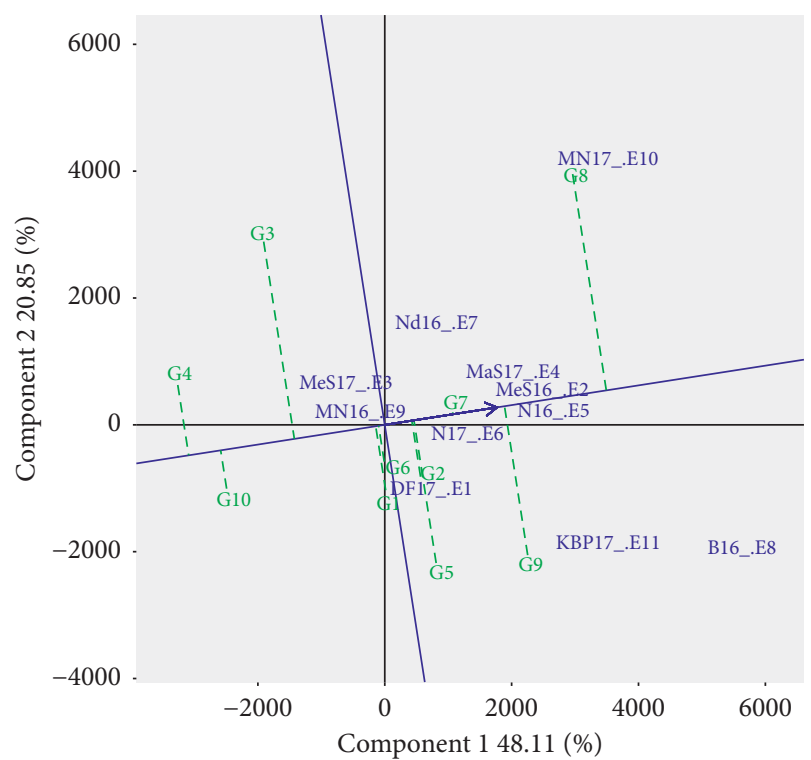

Figure 2: The average-environment coordination (AEC) view showing the performance and stability of varieties in the tested environments based on the genotype focused singular-value partitioning and environment-centered model. The $x$-axis blue singlearrowed line is oriented to the higher mean across the tested environments. The $y$-axis blue line depicts the stability (more closer to the center meaning more stable variety) of the mean. See Tables 1 and 2 for full genotypes and environments code names, respectively.

\section{Discussion}

The present study aimed at identifying high yielding and stable upland rice varieties for cultivation in the groundnut basin agroecological zone by evaluating a set of ten upland rice varieties in different environments. The results showed that the performance of the upland rice varieties was subjected to a strong influence of environments. Such variation may be due to differences in rainfall and soil texture across the different locations where the experimentations were established. Indeed, the rice grain yield in clay soil is known to be higher than that in sandy soil [26] and is closely correlated with total rainfall [27]. The significant effect of genotype by environment (GE) interaction reflected on the differential response of a given upland rice variety in various environments. This difference in response demonstrated that, in addition to the strong effect of the environments, the GE interaction had a remarkable effect on genotypic performance in different environments. The significant effect of GE has been previously noted in rice [28], pearl millet [29], and several other crops. The relative contributions of GE interaction effects for grain yield noted in this study were similar to Katsura et al. [30] results who evaluated 27 rice genotypes in four fields during three consecutive years in the Northern Region of Ghana. In contrast to the results of our study, Sharifi et al. [28] indicated that the GE interaction contributed for $40 \%$ of the total sum of squares of the rice grain yield of genotypes evaluated in Iran.

In our study, the NERICA 14 variety showed the highest grain yield, while the variety CNAX 3031-78-2-1-7 had the lowest grain yield. The grain performance of NERICA 14 was higher than the national average grain yield of the national released upland varieties. The high performance of this variety could be explained by its earliness compared to the other varieties which is an important aspect to consider because of the short rainfall season observed in this Sahelian zone. Farmers have even considered earliness as one of the most important criteria when selecting a variety to grow in this agro-ecological zone.

Identification of mega-environment requires consistency of the mega-environment' delineation and winning cultivars in each mega-environment over several years [17]. In our study, through the GGE biplot, the eleven environments were divided into four sectors each with its own winning cultivar. As a result, the target environments could be divided into four mega-environments. Subsequent evaluation of rice yield performance in the target environments can be done in four environments instead of 11 to save resources. Coupled with the high-yielding criteria, the yield stability is a crucial parameter allowing efficient implementation of released varieties for diverse environments. Our study identified ART3-9-L6P2-B-B, BRS CONAI, and NERICA 8 as the most stable varieties, indicating these materials are not only highly productive but also stable across environments. Consequently, a reliable benefit for Senegalese farmers can be expected no matter the growing location of these three varieties. Reliable identification and release of stable rice genotypes based on the yield stability index were successfully achieved regarding zinc-biofortified rice genotypes [19], productive mutant rice [31], and drought-tolerant rice breeding lines [25]. Considering the fragmented seed market in countries like Senegal [32], it is more profitable and practical for seed companies to produce seeds for varieties that are widely adopted and cultivated, which is the case of varieties that are stable with high performance across a wide agroecological zone. The dissemination of those identified varieties combining stability and productivity would increase rice production and reduce import bill in Senegal.

\section{Conclusions}

We evaluated a set of 10 rice varieties across 11 environments to assess their stability and productivity. We identified the most productive varieties (ART3-9-L6P2-B-B, BRS CONAI, and NERICA 8) within each environment and the most stable and productive varieties across environments. The varieties belonging to the latter category hold great potential to be introduced in varietal release pipeline to offer greater varietal choice for farmers. The use of these varieties could improve the overall rice production in Senegal and decrease rice import.

\section{Data Availability}

The data used to support the findings of this study are included within the supplementary information file.

\section{Conflicts of Interest}

The authors declare no conflicts of interest. 


\section{Acknowledgments}

The authors thank Benjamin Badji and Junior Bruno Ndiaye for their support in collecting data. Funding support was provided by KOPIA Senegal which is duly acknowledged.

\section{Supplementary Materials}

Supplementary table: Yield data of the upland rice genotypes collected in the environments of study. (Supplementary Materials)

\section{References}

[1] W. Wang, R. Mauleon, Z. Hu et al., "Genomic variation in 3,010 diverse accessions of Asian cultivated rice," Nature, vol. 557, 2018.

[2] P. A. Seck, A. Diagne, S. Mohanty, and M. C. S. Wopereis, "Crops that feed the world 7: rice," Food Security, vol. 4, no. 1, pp. 7-24, 2012.

[3] D. Workman, Rice Exports by Country. World's Top Export, 2010, https://www.worldstopexports.com/rice-exports-country/.

[4] V. Balasubramanian, M. Sie, R. J. Hijmans, and K. Otsuka, "Increasing rice production in sub-saharan Africa: challenges and opportunities," Advances in Agronomy, vol. 94, 2007.

[5] M. Sohrabi, M. Y. Rafii, M. M. Hanafi, A. Siti Nor Akmar, and M. A. Latif, "Genetic diversity of upland rice germplasm in Malaysia based on quantitative traits," Science World Journal, vol. 2012, Article ID 416291, 9 pages, 2012.

[6] M. Tuhina-Khatun, M. M. Hanafi, M. Rafii Yusop, M. Y. Wong, F. M. Salleh, and J. Ferdous, "Genetic variation, heritability, and diversity analysis of upland rice (Oryza sativa L.) genotypes based on quantitative traits," BioMed Research International, vol. 2015, Article ID 290861, 7 pages, 2015.

[7] T. T. T. Nguyen, N. M. T. Nguyen, L. H. Hoang, N. Furya, and K. Tuschiya, "Genetic diversity in Vietnamese upland rice germplasm revealed by SSR markers," Journal of the Faculty of Agriculture, Kyushu University, vol. 57, 2012.

[8] S. Rathi, K. Pathak, R. N. S. Yadav, B. Kumar, and R. N. Sarma, "Association studies of dormancy and cooking quality traits in direct-seeded indica rice," Journal of Genetics, vol. 93, 2014.

[9] S. Tang, Y. Zhang, L. Zeng, L. Luo, Y. Zhong, and Y. Geng, "Assessment of genetic diversity and relationships of upland rice accessions from southwest China using microsatellite markers," Plant Biosystems, vol. 144, 2010.

[10] W. Yan, L. A. Hunt, Q. Sheng, and Z. Szlavnics, "Cultivar evaluation and mega-environment investigation based on the GGE biplot," Crop Science, vol. 40, no. 3, pp. 597-605, 2000.

[11] A. Haruna, G. B. Adu, S. S. Buah et al., "Analysis of genotype by environment interaction for grain yield of intermediate maturing drought tolerant top-cross maize hybrids under rain-fed conditions," Cogent Food and Agriculture, vol. 3, 2017.

[12] H. N. A. Mafouasson, V. Gracen, M. Yeboah, G. NtsombohNtsefong, L. Tandzi, and C. Mutengwa, "Genotype-by-environment interaction and yield stability of maize single cross hybrids developed from tropical inbred lines," Agronomy, vol. 8, 2018.

[13] A. J. P. Carcedo, P. A. Pardo, and B. L. Gambin, "Secondary traits explaining sorghum genotype by environment interactions for grain yield," Crop and Pasture Science, vol. 68, 2017.
[14] M. H. Fotokian and K. Agahi, "Biplot analysis of genotype by environment for cooking quality in hybrid rice: a tool for line $\times$ tester data," Rice Science, vol. 21, no. 5, pp. 282-287, 2014.

[15] M. Balestre, V. Borges, A. A. Soares, and M. Reis, "Stability and adaptability of upland rice genotypes," Crop Breeding and Applied Biotechnology, vol. 10, 2010.

[16] H. G. Gauch, "A simple protocol for AMMI analysis of yield trials,” Crop Science, vol. 53, no. 5, pp. 1860-1869, 2013.

[17] W. Yan, M. S. Kang, B. Ma, S. Woods, and P. L. Cornelius, "GGE biplot vs. AMMI analysis of genotype-by-environment data," Crop Science, vol. 47, 2007.

[18] T. L. B. Acuña, H. R. Lafitte, and L. J. Wade, "Genotype $\times$ environment interactions for grain yield of upland rice backcross lines in diverse hydrological environments," Field Crops Research, vol. 108, 2008.

[19] M. A. Inabangan-Asilo, B. P. Mallikarjuna Swamy, A. F. Amparado, G. I. L. Descalsota-Empleo, E. C. Arocena, and R. Reinke, "Stability and $\mathrm{G} \times \mathrm{E}$ analysis of zinc-biofortified rice genotypes evaluated in diverse environments," Euphytica, vol. 215, 2019.

[20] A. L. Nassir, "Genotype $\times$ Environment analysis of some yield components of upland rice (oryza sativa L.) under two ecologies in Nigeria," International Journal of Plant Breeding and Genetics, vol. 7, 2013.

[21] S. Ferrari, P. Pagliari, and J. Trettel, "Optimum sowing date and genotype testing for upland rice production in Brazil," Scientific Reports, vol. 8, 2018.

[22] R. Pushpam, S. Manonmani, N. Vishnu Varthini, and S. Robin, "Studies on yield, root characters related to drought tolerance and their association in upland rice genotypes," Electronic Journal of Plant Breeding, vol. 9, 2018.

[23] A. B. Heinemann, C. Barrios-Perez, J. Ramirez-Villegas et al., "Variation and impact of drought-stress patterns across upland rice target population of environments in Brazil," Journal of Experimental Botany, vol. 66, 2015.

[24] J. Adjebeng-Danquah, J. Manu-Aduening, V. E. Gracen, I. K. Asante, and S. K. Offei, "AMMI stability analysis and estimation of genetic parameters for growth and yield components in cassava in the forest and Guinea savannah ecologies of Ghana," International Journal of Agronomy, vol. 2017, Article ID 8075846, 10 pages, 2017.

[25] R. O. Torres and A. Henry, "Yield stability of selected rice breeding lines and donors across conditions of mild to moderately severe drought stress," Field Crops Research, vol. 220, 2018.

[26] F. Dou, J. Soriano, R. E. Tabien, and K. Chen, "Soil texture and cultivar effects on rice (oryza sativa, L.) grain yield, yield components and water productivity in three water regimes," PLoS One, vol. 11, no. 3, Article ID e0150549, 2016.

[27] K. Saito, B. Linquist, B. Keobualapha, K. Phanthaboon, T. Shiraiwa, and T. Horie, "Cropping intensity and rainfall effects on upland rice yields in northern Laos," Plant and Soil, vol. 284, no. 1-2, pp. 175-185, 2006.

[28] P. Sharifi, H. Aminpanah, R. Erfani, A. Mohaddesi, and A. Abbasian, "Evaluation of genotype $\times$ environment interaction in rice based on AMMI model in Iran," Rice Science, vol. 24, no. 3, pp. 173-180, 2017.

[29] P. Sumathi, M. Govindaraj, and P. Govintharaj, "Identifying promising pearl millet hybrids using AMMI and clustering models," International Journal of Current Microbiology and Applied Sciences, vol. 6, no. 2, pp. 1348-1359, 2017.

[30] K. Katsura, Y. Tsujimoto, M. Oda et al., "Genotype-by-environment interaction analysis of rice (Oryza spp.) yield in a 
floodplain ecosystem in West Africa," European Journal of Agronomy, vol. 73, pp. 152-159, 2016.

[31] Y. Oladosu, M. Y. Rafii, N. Abdullah et al., "Genotype $\times$ Environment interaction and stability analyses of yield and yield components of established and mutant rice genotypes tested in multiple locations in Malaysia," Acta Agriculturae Scandinavica. Section B. Soil and Plant Science, vol. 67, 2017.

[32] D. J. Spielman and M. Smale, "Policy options to accelerate variety change among smallholder farmers in South Asia and Africa South of the Sahara," IFPRI Discussion Papers 1666, International Food Policy Research Institute (IFPRI), Washington, DC, USA, 2017. 